\title{
ON THE JAMES TYPE CONSTANT AND VON NEUMANN-JORDAN CONSTANT FOR A CLASS OF BANAŚ-FRA̧CZIECK TYPE SPACES
}

\section{CHANGSEN YANG AND XIANGZHAO YANG}

Abstract. As a generalization of Banaś-Frączieck space, the space $X_{\lambda, p}$ that denotes $\mathbb{R}^{2}$ endowed with the norm

$$
\|x\|_{\lambda, p}=\max \left\{\lambda\left|x_{1}\right|,\|x\|_{p}\right\}
$$

for $\lambda>1, p \geqslant 1$ and $x=\left(x_{1}, x_{2}\right) \in \mathbb{R}^{2}$ is well defined. In this note, the exact value of the the James type constants $J_{X_{\lambda, p}, t}(1)$ and von Neumann-Jordan constant $C_{N J}\left(X_{\lambda, p}\right)$ about this space for $p \geqslant 2$ are investigated.

Mathematics subject classification (2010): Primary 46B20; Secondary 46B99.

Keywords and phrases: Jordan-von Neumann constant, modulus of convexity, Banaś-Frączieck type space, James type constant.

\section{REFERENCES}

[1] J. A. Clarkson, The von Neumann-Jordan constant for the Lebesgue space, Ann. of Math., 38 (1937), 114-115.

[2] R. C. JAMES, Uniformly nonsquare spaces, Ann. of Math., 80 1964, 542-550.

[3] J. GAO, K. S. LAU, On two classes of Banach spaces with uniform normal structure, Studia Math. 99(1991), 41-56.

[4] Y. TAKAHASHI, Some geometric constants of Banach spaces - a unified approach, Banach and function spaces II, Yokohama Publ., Yokohama, (2008), 191-220.

[5] J. Alonso, E. LloRENS-Fuster, Geometric mean and triangles inscribed in a semicircle in Banach spaces, J. Math. Anal. Appl. 340 (2008), 1271-1283.

[6] J. Banaś And K. FrącZeK, Deformation of Banach spaces, Comment. Math. Univ. Carolinae 34 (1993), no. 1, 47-53.

[7] C. YANG, Jordan-von Neumann constant for Banaś-Fraczek space, Banach J. Math. Anal. 8 (2014), no. $2,185-192$.

[8] C. YAng, Y. WANG, Some properties of James type constant, Appl. Math. Lett. 25 (2012), 538-544. 